\title{
A Critical review on friction stir based processes
}

\author{
${ }^{1}$ M. Puviyarasan, ${ }^{2}$ L. Karthikeyan, ${ }^{3} \mathrm{C}$. Gnanavel, ${ }^{4} \mathrm{~K}$. Dhineshkumar \\ ${ }^{1}$ Associate Professor, ${ }^{2}$ Professor, ${ }^{3,4}$ Under-Graduate Students, \\ Department of Mechanical Engineering, Panimalar Engineering College, Chennai - 600 123, India. \\ muthupuvi@gmail.com
}

\begin{abstract}
Friction stir based processes are solid state processes which significantly contribute to joining/processing of materials and surface property enhancement. It replaces conventional joining/processing techniques owing to their unique features such as reduced distortion, reduced porosity defect, reduced heat affected zone (HAZ), no requirement of shielding gas, eco-friendly etc. Also, It enhances the mechanical and metallurgical properties of the material namely grain refinement, microstructure modification, homogenization, corrosion, fatigue, wear and hardness, which are laborious to attain in fusion welding. This review approaches the detailed study on friction stir-based processes, starting from friction stir welding and their applications in present scenario.
\end{abstract}

Keywords: Friction stir welding, Friction stir processing, Friction stir spot welding, Friction stir riveting, Friction stir cladding, Friction stir channeling.

\section{INTRODUCTION}

New materials and innovative production processes are constantly emerging in order to face the new challenges aiming at lower environmental impact, more technological innovation and reducing the life-cycle costs through structural weight reduction or reducing manufacturing costs. The invention of friction stir welding (FSW) process in 1991 by the welding institute (TWI), UK, was considered as a most significant development in metal joining in a decade. Though it was originally developed to join aluminum and it's alloys[1] the recent developments extends it's possibility of applying the technique for magneisum, copper, steel based alloys, brass and plastic materials[2,3]. The advancement in FSW technique is extremely high after the columbia shuttle failure due to which NASA started focusing their research in the field of FSW.

The basic principle of FSW is remarkably simple. It is a solid state joining process in which specimens are joined by stirring them along a line of interest without fusion. Thomas et al., Rai et al. [4], and Zhang et al. [5] comprehensively reviewed FSW tools and development. Threadgill et al. gave a critical overview of FSW of aluminum alloys. Mishra and Ma [6] gave a systematic review on FSW and friction stir processing (FSP). Tutum and Hattel [7] reviewed the numerical optimization of FSW and its challenges and Cam analyze about the FSW development for different metals and alloys.

In recent years, several other friction stir-based processes have been derived from the FSW process and they have been successfully adapted to various engineering applications. The friction stir-based processes are given in Fig. 1.

In this process material is subjected to intense material mixing via. Plastic deformation and resulting in significant grain refinement, densification and homogeneity of processed zone [8]. This process can be employed for joining-bonding metallic and plastic materials, surface hardening, modification and control of grain size in a localized area, composite manufacturing, surface cladding and friction stir- channeling. Figure: 2 show the pictorial view of working model.



(Source: Sergio MOT. 2011)

Figure 1. Various friction stir based processes

Though several review papers have been published on various aspects of FSP/ FSW in recent years, this paper aims in providing a comprehensive overview of friction stir related processes which plays a prominent role in various industrial applications.

\section{FRICTION STIR WELDING (FSW)}

It is a solid-state joining technology that has become well established for producing high-quality welds of aluminium alloys, which has wider application in aerospace and defence industry [10]. It uses a rotating, non-consumable tool which consists of a pin and a concentric shoulder, whose diameter is usually thrice that of pin [11] (Figure 2).

From the operational viewpoint, a friction stir welding run can be done by three phases namely (a) plunge and dwell (b) traverse, (c) retract. Figure 3 shows various steps involved in Friction Stir Process. At the start of the plunge phase, 
rotating friction stir tool is gradually inserted into the work piece and the rubbing action creates heat. The process of tool insertion continues until the tool shoulder is in intimate contact with the work piece surface.

At this stage, the tool shoulder and pin surface contribute to the frictional heating and force applied along the axis of the tool starts to drop as the metallic work piece reaches critical temperature for plastic flow [12]; plasticized flow of material is influenced by tool profiles, tool dimensions and process parameters $[13,14]$.

Since the pin produces the stirring action at the intersection, metal transfer takes place from advancing side to retreating side and vice versa. The advancing side refers to the side of half plate which faces the clockwise direction of rotation of tool along the welding direction and another plate is referred as retreating side. In most of the cases the hardness of advancing side is more than retreating side, because the repeated metal transfer gives more refined grains. Once the work piece and tool interface is adequately heated up, the tool is traversed along the preferred direction to achieve processing. At the end of the joining process, the tool is retracted from the work piece.

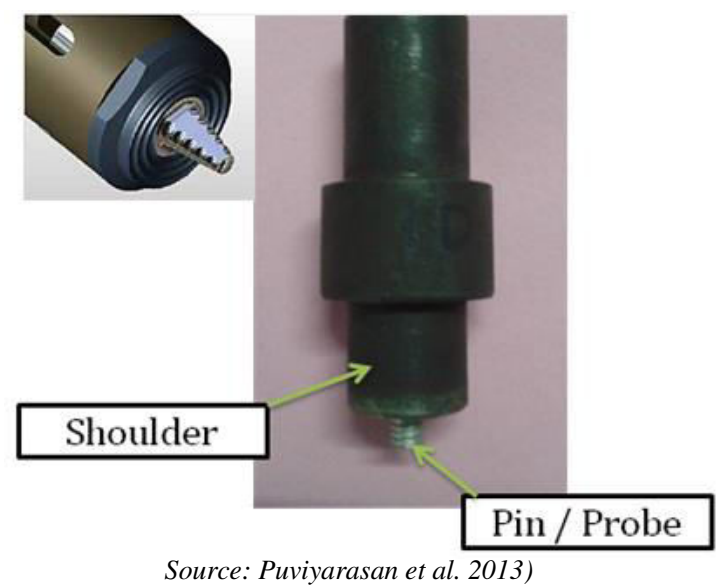

Figure 2. Typical view of non consumable tool



Figure 3. Steps involved in Friction Stir Process

\section{A. Various Zones in FSW}

Various zones has been accounted in FSW are as follows, a. Stir Zone (SZ) or Nugget zone, b. Thermo mechanically affected Zone (TMAZ), c. Heat Affected Zone (HAZ), d. Unaffected or parent material. Figure 4 shows various regions in FSW. The characteristics of each zones are given below [6], Stir Zone (SZ): The region that undergoes intense plastic deformation, thermal exposure and material movement due to the stirring of tool shoulder and pin is called stir zone or nugget zone. Fine recrystallized grains are observed in this zone. This region is usually referred as dynamically recrystallized zone. Under certain prevailing settings, an onion ring structure was noticed in the nugget zone.



Thermo-Mechanically Affected Zone (TMAZ): The uniqueness of the FSW/FSP process lies in the creation of a transition zone between the parent material and the nugget zone called thermo-mechanically affected zone (TMAZ). TMAZ is the region surrounding the nugget zone. This zone named as TMAZ because it experiences both temperature and mechanical deformation during processing.

Heat Affected Zone (HAZ): The region next to TMAZ is Heat affected zone, which does not undergo any plastic deformation, but experiences only a thermal cycle. There is a decrease in the hardness due to differences in the grain structure. The HAZ retains the same grain structure as that of the parent material.

Unaffected or Parent Metal: The material far away from the processed area, which has not been deformed is termed as unaffected or parent metal. Despite experiencing a thermal cycle from the process zone, the microstructure or mechanical properties does not get affected by heat.

\section{B. Improvement in Mechanical Properties}

G.Rambabu et al. did a work on optimization of FSW parameters on AA2219 Al alloy; His research indicates that the shape of the pin has a significant effect on the joint structure and the corrosion properties. For his work, he used five different pin profiles as shown in figure $5 . \mathrm{He}$ concluded that the best quality weld was acquired using hexagon tool profile. Pin geometry affects the nugget microstructure, the grains in the nugget region experienced high temperature and turbulent material flow resulting in severe plastic deformation [15]. Very fine grains are formed due to dynamically recrystallization compared to weld nugget made with other tool, the weld made with hexagon tool profile shows very fine grain distribution compared to other (figure 6). 


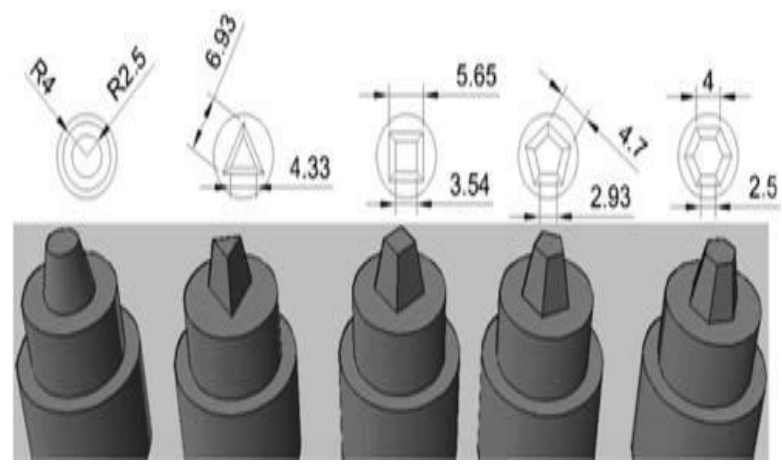

(Source: G. Rambabu et al. 2015)

Figure 5. Various tool profiles namely conical, triangular, square, hexagonal, and pentagonal.



(Source: G.Rambabu et al.2015)

Figure 6. optical micrograph of weld nugget zone with tool profile a.base material, b.conical, c.triangular, d.square profile, e.pentagon, f.hexagon

Process parameters involved in FSW was analyzed by cavaliere [16]. The results shows that, ductility increases as increasing the welding force from low to intermediate values of the revolutionary pitch and increases as increasing the tool inclination angle. Ultimate Tensile strength increases as increasing the welding force. He also stated that the residual stress increases as increasing the base material hardness up to a maximum and then they start to decrease as increasing the base material hardness [16]. The advantages and limitation of the friction stir welding process is presented in [6].

\section{Submerged Friction Stir Welding}

Submerged Friction Stir welding (SFSW) is an improved method for microstructural modification of materials through severe plastic deformation. It is similar to FSW but the entire processing of the bulk samples are submerged in a medium like water. Figure 7 shows the illustrative view of underwater friction stir welding. Sakurada was the first to use submersion in a rotary friction weld for 6061 aluminum alloys. From their study, it was possible to generate enough friction for welding even though the samples were submerged [17].

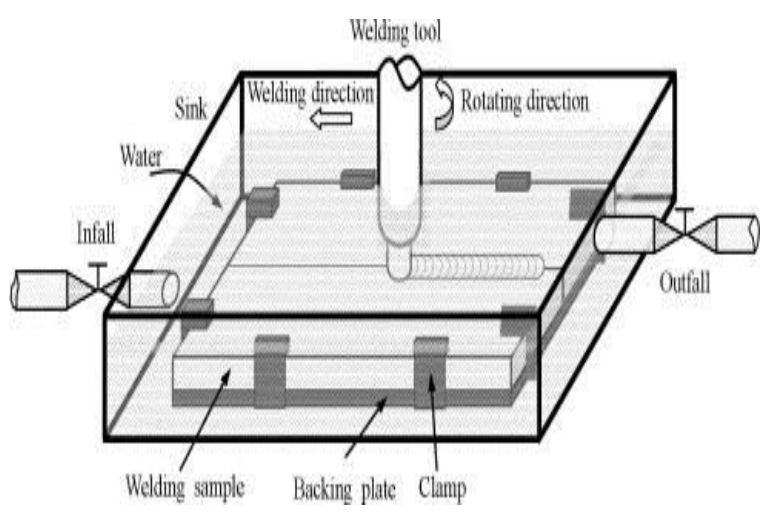

(Source: Huijie Zhang et al. 2013)

Figure 7. Illustrative view of underwater friction stir welding



Figure 8. Tensile properties of different joints

\section{Advantages of Submerged FSW over Normal FSW}

The tensile properties of submerged friction stir welded joints of aluminium bar have a tensile strength of 341Mpa equivalent to $79 \%$ of the base metal [18]

So it can be seen that by underwater friction stir processing the tensile properties can be greatly improved. Figure 8 tensile properties of different joints. However, the elongation of underwater FSW joints only reaches $7.6 \%$ which is lower than of the normal joint [18].

\section{FRICTION STIR SPOT WELDING (FSSW)}

FSSW is an innovative advancement of friction stir welding developed for thin sheet alloys [19]. It is an approach of seam welding adopted for spot like joining on a low density thin sheet metal including copper and magnesium alloys at short cycle time.

In FSSW, plunging of a non-consumable rotating tool carried out in a controlled manner, Frictional action occurs at the interface between the plunging tool and workpiece that tends to soften the surface of the material around the tool, plasticization of the material is being attained by continuous application of downward force along the axis of the tool and the combined rotational action could create the material flow in circumferential and axial direction of the tool [20]. 
Friction stir spot welding not only depends on the process parameters but also the nature of the material. Figure 9 shows phases involved in FSSW as in the following order, tool rotation, plunging, stirring and drawing out [21].

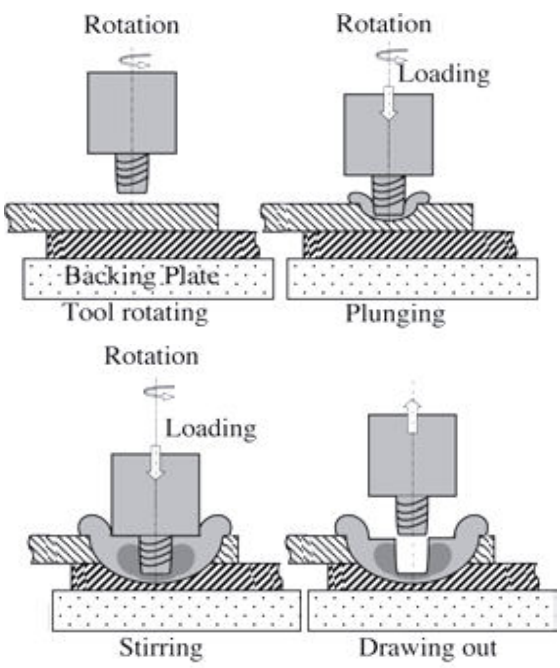

(Source: Ugur Özdemir et al. 2012)

Figure 9. Schematic illustration of FSSW process

During execution, material under the shoulder would move to the base of tool (1), because of the rotational action there will be spiral shaped flow along the surface of the threaded pin towards bottom as a result of direction of dragging force of the rotation (2), Once the flow reaches the bottom of the tool, the material is forced towards the top and outside, then it come back to the pin direction depends on the helical rotation (3). Non threaded cylindrical pin limits the uninterrupted flow of material in upright direction [22]. Figure 10 shows the material flow during the FSSW.



(Source: Boiocchi F et al. 2012)

Figure 10. Material flow during the friction stir spot welding

Mukuna P.Mubiayi et al. has conducted a FSSW on dissimilar materials ( $\mathrm{Al}$ and $\mathrm{Cu}$ ) using various process parameters. Their result showed that the hardness values were high in the stir zone for all the produced spot samples, this was attributed to the presence of hard and brittle intermetallic compounds, although they are in low concentration and the microstructure showed good material mixing, a distribution of copper particles and fragments with uneven shapes and a variety of sizes in the aluminium matrix [23].

\section{A. Refill Friction Stir Welding (RFSSW)}

At the end of drawing out in FSSW, plunging pin leaves a exit hole at the surface. Because of the presence of keyhole, whenever the welded part is subjected to axial load chances for the occurrence of fracture would be more; in order to prevent this situation GKSS of Germany invented a process that would fill the keyhole and this method was called as refill friction stir spot welding (RFSSW) process [24]. Figure 11 shows the schematic representation of process variants in RSSW.


(Source: Soldagem Insp. São Paulo et al. 2009)

Figure 11. Schematic representation of process variants in RFSSW, sleeve plunge variant is represented at the left side and the pin plunge variant is represented at the right side, At the left side a) sleeve plunges towards the workpiece, b) sleeve retraction and pin plunge, c) retraction of pin, At the Right side a) pin pluges towards the workpiece, b) pin retraction and sleeve plunge, c) retraction of sleeve. 
This process uses tool assembly consisting of clamping ring, sleeve and pin. Clamping ring holds the plates firmly in a position and it also constraints the material flow [25], sleeve and pin rotates in an opposite manner and these were translated independently in axial direction, this controlled movement is responsible for welding action,



(Source:Venukumar et al. 2013)

Figure 12. Comparison graph between conventional FSSW and RFSSW for static shear strength,

Venukumar et al has compared the static shear strength of materials on both FSSW and RFSSW. It is found to be the static shear strength of RFSSW material is $38 \%$ higher than the conventional FSSW and the comparison graph (figure 14) shows that the static shear strength of the material could be increased by increasing the plunging pin rotational speed. [26]

\section{FRICTION STIR RIVETING (FSR)}

It is feasible to employ both aluminium and magnesium in a single application so as to attain good weight reduction at an appropriate light weighting cost, but it is exceptionally hard to fusion weld to $\mathrm{Al}$ to $\mathrm{Mg}$ because thick and brittle intermetallic components [27]. To achieve the above things, Yongbing Li et al. proposed a new joining process, named it as friction stir riveting (FSR). It eliminates the pre-drill, a hole for rivet insertion.

Figure 13 shows the schematic illustration of friction stir riveting for two dissimilar metals. This process involves four stages as follows, Rivet feed stage(a) in which the specimen is clamped on to the die, and the rivet moves down to contact the specimen and at the same time rivet rotate at set speed, Hot riveting stage(b) in which rotating rivet pierces into the top specimen and at the same time softens and introduces into that specimen, In situ friction stage(c) in which the rivet stops feeding downward but keeps rotating for a set dwell time to create the high temperature condition for solid-stage joining.
Off stage (d) in which the rotational motion of rivet is quickly stopped to produce stationery contact between rivet and surrounding metals so that the solid-state joining will be formed. Better static and fatigue strength could be attained in Friction stir riveting when compared with that of convention spot welding [28]

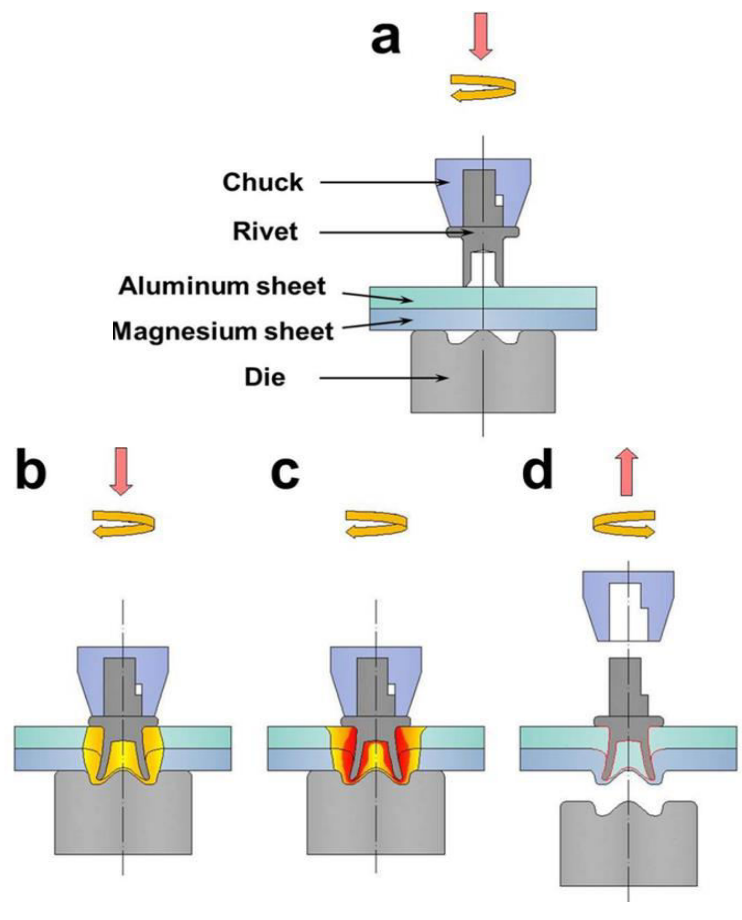

(Source: Yong Bing Li et al. 2013)

Figure 13. Illustration of Friction stir riveting for two dissimilar metals, a) clamping of thin sheets,

b) plunging of rivet, c) generation of heat because of friction, d) retraction of tool, eventually the protruded rivet is trimmed off from the material surface.

\section{FRICTION STIR PROCESS}

Friction stir process is a method for changing the properties of a metal through intense, localized plastic deformation. The precursor of this technique is friction stir welding and the schematic is shown in Figure 14.

During this process, the material goes through intense plastic deformation and it results in significant grain refinement. The grain refinement occurs on the first material while mixing with the second material, severe localized distortions leads to breaking up of second phase particles and uniform distribution of grain, it creates a microstructure with fine, equiaxed grains [32].

FSP changes the physical properties without changing its physical state which helps engineers create things such as "high-strain-rate super plasticity". This helps to alter the various mechanical properties on variety of materials. Some results proved the tensile strength were improved by FSP, in a test with an actively cooled magnesium-alloy workpiece, the micro hardness was almost tripled in the area of the friction stir processed seam. This technique improves the formability characteristics of the material in a prominent way [33]. 


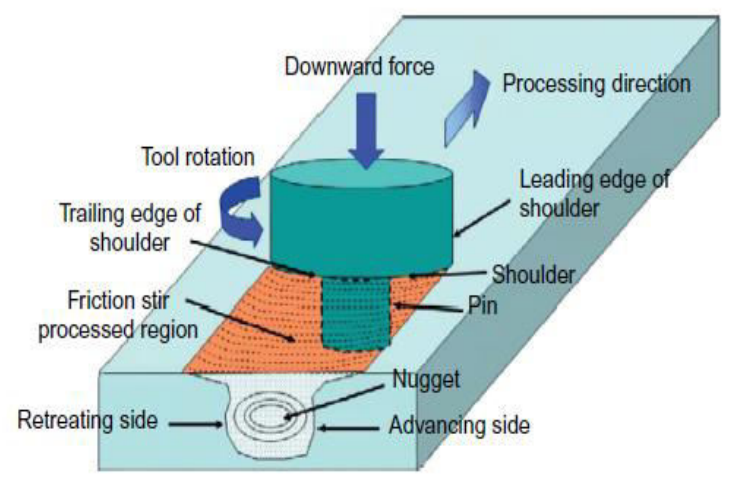

(source: Rajiv S.Mishra, Christhoer B.Smith. 2011)

Figure 14. Schematic diagram of friction stir Process

Hofmann et al. was the first to use submerged friction stir processing for creating ultra fine grained materials and he concluded that addition of water dramatically reduces the amount of conductive heat flow typically generated by multiple passes of FSP done in air. In addition, materials that exhibit slower recrystallization kinetics may yield bulk grain sizes less than $100 \mathrm{~nm}$ by the submerged FSP method. He also mentioned that his work can be continued by attempting SFSP experiments with super-cooled fluids to increase the cooling rate in the sample [34]

Submerged FSP is superior to FSP in the air for creating ultra-fine grained bulk sample due to a reduction in heat load to the sample. Using underwater FSP grain size of less than $200 \mathrm{~nm}$ can be achieved. This is achieved due to faster cooling rate [35].

\section{A. Fabrication of Composites}

This Metal Matrix Composites (MMC) can also be fabricated by FSP. It is the process of mixing metals and other powders or non-metals or metals to increase the properties of the base metal. The use of the FSP technique results in the intense plastic deformation and mixing of material in the processed zone; incorporate the ceramic particles into the metallic substrate plate, to form the surface/Bulk composites [36]. Figure 15 show the schematic diagram for the fabrication of composites. A groove can be cut on the plate, and the particles filled into the groove. With deeper grooves being cut, it is possible to fabricate bulk composites via. FSP [37, 38].

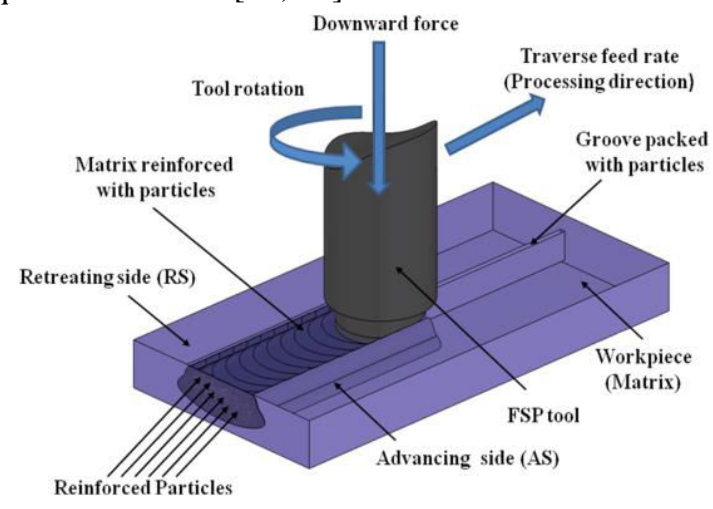

(Source: Puviyarasan et.al. 2012)

Figure 15. Schematic diagram for the fabrication of composites
The composites fabricated through FSP confirmed improved hardness and strengths. By increasing the required reinforcement (powders) the properties can be varied [39].

Solevmani et al (2012) have examined the microstructure of $\mathrm{Al} 5083 / \mathrm{SiC}_{\mathrm{p}}+\mathrm{MoS}_{2}$ composites fabricated via FSP (Figure 16). It has been found that the mean grain of the material reduced considerably by processing in FSP. The grain enhancement is caused by dynamic recrystallisation phenomena and it is evident that SEM micrograph shows uniform distribution of reinforcement within the surface [40].

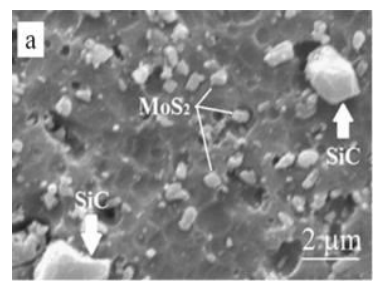

(a) distribution of reinforcement particles in stir zone

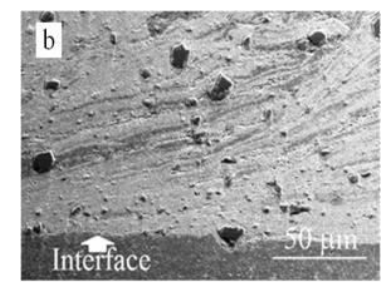

(b) proper bonding in hybrid composite layer-matrix
(Source: Soleymani el al. 2012 )

Figure 16. Microstructure of $\mathrm{Al} 5083 / \mathrm{SiC}_{\mathrm{p}}+\mathrm{MoS}_{2}$ composites fabricated using FSP

The ever increasing demand to improve the safety and comfort of automobiles has lead to the addition of various electronic and other components within automobiles. As a result the weight of the automobile and the accompanied fuel consumption tend to increase. This has paved the way to the usage of polymers and polymer nano-composites with good strength, light weight and high wear resistance.

Thermal conductivity of metallic materials are high than that of the polymers. Because of this, fabrication of polymeric composites faces some challenges in FSP that uses conventional FSP tool, to overcome this difficulty Balamugundhan et al. developed a new tool and fabricated a high density poly ethylene (HDPE) nano-composite (Figure 17). The designed FSP tool consists of thrust bearing, cylindrical rotating pin and stationary shoulder. During Friction Stir processing, the thrust bearing separates the shoulder from the FSP tool and keeps it stationary relative to the pin. The stationary shoulder was fabricated using AA6061 Aluminum alloy, chosen for its superior strength and higher thermal conductivity [41].

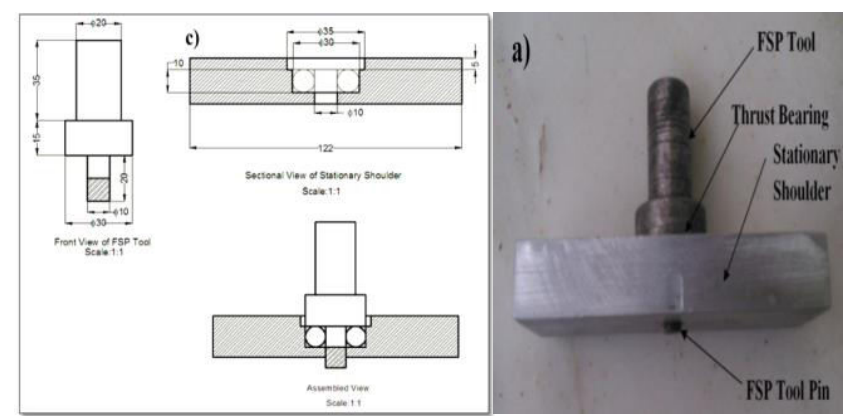

(Source: Balamugundan et al. 2018)

Figure 17. Dimensions of the designed FSP tool, the FSP tool with stationary shoulder 
It was concluded that the polymeric composites can be fabricated successfully by using stationary shoulder tool and his results showed good mechanical properties [41]. On the other hand, the same polymeric composites fabricated using conventional FSP technique under same process parameters displayed huge defects and low mechanical properties, Usually process parameters of this technique influences the predominant properties of the synthesized composite materials [42-44]

\section{B. Friction Surface Cladding}

This technology facilitates the deposition of solid-state by means of filler material on a substrate with good quality mechanical bonding. Figure 18 shows the side view and side view of Friction stir cladding process. In this technique there is no protruded pin, instead of that flat shoulder is being used to plasticize the materials at the top.
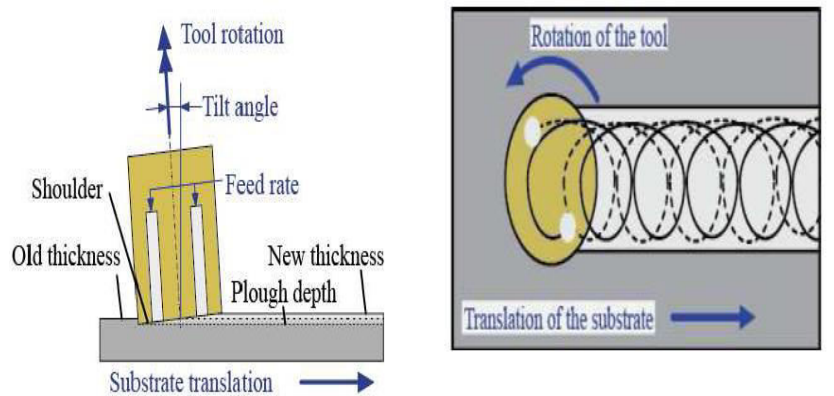

(Source: van der Stelt el al. 2013)

Figure 18. The side view and top view of Friction stir cladding process

The friction surface cladding process is strongly connected to the friction surfacing process as both processes attach a clad layer on a substrate [45]. The clad layer consists of plasticized layers of consumable rods which are put down by the rotation under pressure. It enables the deposition of one or more consumable rods of equal or different material in a controlled manner, whereas friction surfacing consists of only one cylindrical rotating rod [46]. Significant process parameters of FSC are the rotational speed, traverse feed, and applied downward force. Wear resistance of the material can improved by the imparting the clad surface over the material using this surface cladding technique. By using suitable material as a substrate corrosion resistance can also be improved. [47]

\section{Friction Stir Channeling}

When performing FSW, a defect named as "wormhole" is generated if the parameters and tool shoulder contact are not appropriate. In FSC this defect formation is converted into a manufacturing technique which can be applied to heat exchanger and mold applications. The FSC results from the application in the visco-plasticized workpiece material of an upward action along the threaded probe unified with an outward action along the scrolled shoulder. Figure 19 shows schematic illustration of the FSCn process fundaments. In this process the profiled pin is rotated in that the material flow is upward towards the tool shoulder, beginning clearance is provided between the workpiece and the shoulder and this is the most important difference between FSC and the conventional FSW.

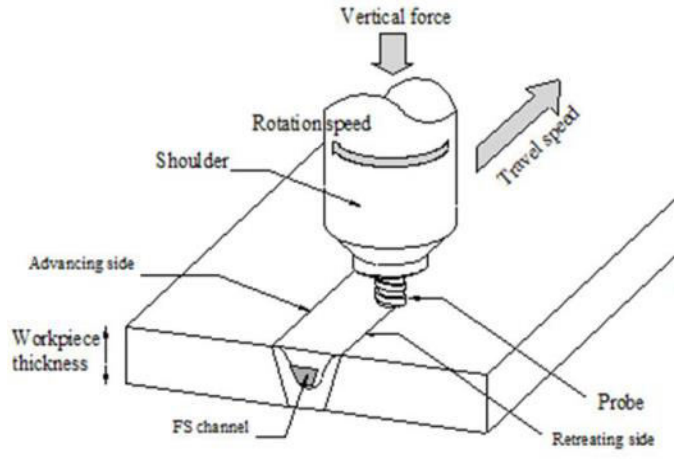

(Source: Pedro Vilaca et al. 2011).

Figure 19. Schematic illustration of the FSC process



(Source: Balasubramaniyan et al. 2011)

Figure 20. Cross-section of a channel showing the different process regions

During channelling, rotating profiled pin generates an upward force, due to which parting of the plasticized material occurs around the pin from the plasticized material. As the plasticized material is shifted upwards through the rotation of the pin and it is deposited on the top of the nugget beneath the shoulder surface a channel is formed [48].

The shapes of the channels attained from FSC shown in Figure 20 are nearer to an oval or ellipse. The channel shapes normally vary non-linearly with the process parameters (the rotational speed and traverse feed). The area of the channel shrinks with an increase in the rotational speed of the tool and for the same rotational speed increases with an increase in the traverse feed. The hardness values are superior in the stirred zone - the channel nugget - which grain refinement contributes to the increase of hardness [49].

The details about the various processes such as Friction Stir Scribe (FSS), Stationary Shoulder Friction Stir Welding (SSFSW), Reverse Dual-Rotation Friction Stir Welding (RDRFSW), Bobbin Tool Friction Stir Welding (BTFSW), Friction Stir Extrusion (FSE), Friction Stir Additive Manufacturing (FSAM), Friction Surfacing (FS), and Friction Stir Forming (FSF) are not presented here due to a limitation on space. 


\section{SUMMARY AND HIGHLIGHTS}

In this study, different aspects of friction stir based techniques have been illustrated.

- Friction stir welding is an established technique with its unique characteristics such as low shrinkage and distortion even in long welds of around 1000 meters, low heat affected zone, free of spatter and porosity discrepancies.

- FSW is appropriate for joining similar, dissimilar metals and alloys including aluminum, steel, copper, magnesium, nickel, zinc and their alloys, plastics, etc.

- It is evident that FSW tool controls the amount of material stirred and frictional heat. Therefore, geometry of pin and shoulder are deciding factor to attain good quality welds.

- During FSW, Lower heat input, the stirring effect, and refined microstructure contributes for improvement in the mechanical properties.

Further, developments in FSW leads to invention of friction stir based techniques.

- Superior mechanical properties are possible when the processing is done under the water; it helps to attain extensive grain structure and extraordinary ultimate tensile strength than the conventional FSW.

- Friction stir spot welding replaces conventional spot welding which has wide scope in the field of automobile engineering. In industries, application of conventional spot welding is being replaced by FSSW to weld thin sheet metals. To eliminate keyholes in FSSW, RFSSW coming into existence, it results in higher static shear strength and fatigue of $\mathrm{Al}$ alloys. Better corrosion resistance could also be achieved in refill FSSW.

- Friction stir riveting can be applied to thicker or thinner sheets and a wide-range of materials such as metal matrix composites carbon fiber reinforced thermoplastics and high-strength alloys. This technique was mainly aimed to dwindle the weight of conventional rivets. Even if the rivet diameter is half of the size of weld nugget, fatigue life could be extended one or two orders than that of resistance spot welding

- Friction stir process eliminates porosity defects on surface, helps in improving the prominent metallurgical properties of the specimen. The quantity of heat generation during FSP is a critical issue to fabricate a defect free FSP zone. At present, fabrication of extensive surface composites was made possible by FSP. The selection of optimum parameters is crucially important to produce a good quality composite zone using FSP.
- The Friction stir cladding process spread outs the potential to clad or mix materials on a substrate in the solid state. This technique is extensively used in nuclear reactors, cladding of reactor vessel internals to improve erosion, corrosion, and wear resistance.

- Friction stir channeling as a manufacturing process for creating channels that can be used in heat exchangers and molds in larger extend. The superior productivity of FSC compared to other technologies is a most important opportunity for it to be employed in a range of industries.

\section{REFERENCES}

[1] W.M. Thomas, D.G. Staines, I.M. Norris, R. de Frias, Friction stir welding tools and developments, Weld. World 47 (2003) 10-17.

[2] Carlone P, Astarita A, Palazzo GS, Paradiso V, Squillace A (2015) Microstructural aspects in $\mathrm{Al}-\mathrm{Cu}$ dissimilar joining by FSW. Int $\mathrm{J}$ Adv Manuf Technol. doi:10.1007/s00170-015-6874-z

[3] Abdolahzadeh A, Omidvar H, Safarkhanian MA, Bahrami M (2014) Studying microstructure and mechanical properties of $\mathrm{SiC}$ incorporated AZ31 joints fabricated through FSW: the effects of rotational and traveling speeds. Int J Adv Manuf Technol 75:189-196. doi:10.1007/s00170-014-6205-9

[4] R. Rai, A. De, H.K.D.H. Bhadeshia, T. DebRoy, Review: friction stir welding tools, Sci. Technol. Weld. Join. 16 (4) (2011) 325-342.

[5] Y.N. Zhang, X. Cao, S. Larose, P.Wanjara, Review of tools for friction stir welding and processing, Can. Metall. Q. 51 (3) (2012) 250-261.

[6] R.S. Mishra, Z.Y. Ma, Friction stir welding and processing, Mater. Sci. Eng. R Rep. 50 (1-2) (2005) 1-78.

[7] C.C. Tutum, J.H. Hattel, Numerical optimisation of friction stir welding: review of future challenges, Sci. Technol. Weld. Join. 16 (4) (2011) 318-324.

[8] Threadgill PL, Leonard AJ, Shercliff HR, Withers PJ (2009) Friction stir welding of aluminium alloys. Int Met Rev 54(2):49-93.

[9] Sergio MOT (2011) Design and advanced manufacturing of aircraft structures using friction stir welding, a dissertation submitted to the Faculty of Engineering of the University of Porto for the degree of Doctor of Philosophy in Leaders for Technical Industries of the MITPortugal Program, Porto.

[10] Thomas WM, Nicholas ED, Needham JC, Murch MG, Temple Smith P, Dawas CJ. Int. Patent Appl. No. PCT/GB92/02203 and GB Patent Appl.9125978.8, Dec. 1991; U.S Oct. 1995: Patent Appl.No.5460317.

[11] R.Lokesh, V.S.Senthil Kumar, C.Rathinasuriyan, R.Sankar, Optimisation of process parameters tool profile, rotational speed for submerged friction stir welding of AA6063 alloy, e.ISSN:2320-8163.

[12] Nandan R, DebRoy T, Bhadeshia HKDH. Recent advances in friction-stir welding. Process, weldment structure and properties. Prog Mater Sci 2008;53:980e1023.

[13] Bagheri Hariri Mohiedin, Gholami Shiri Sajad, Yaghoubinezhad Yadollah, Mohammadi Rahvard Masoud. The optimum combination of tool rotation rate and traveling speed for obtaining the preferable corrosion behavior and mechanical properties of friction stir welded AA5052 aluminum alloy. Mater Design 2013;50:620e34.

[14] Shigematsu I, Known YJ, Suzuki K, Imai T, Saito N. Joining of 5083 and 6061 aluminum alloys by friction stir welding. J Mater Sci Lett2003;22(5):353e6.

[15] G.Rambabu et al, Optimization of FSW parameters for improved corrosion resistance of AA219 alloys, Defence technology 11(2015) 330-337.

[16] Pasquale Cavaliare, Analysis of processing parameters affecting mechanical behaviour, Procedia CIRP 11(2013) 139-144

[17] Sakurada D, Katoh K, Tokisue H. Underwater friction welding of 6061 aluminum alloy. J Jpn Inst Light Met 2002;52(2):2. 
[18] LIU Hui-jie, ZHANG Hui-jie, HUANG Yong-xian, YU Lei, (2010), "Mechanical properties of underwater friction stir welded 2219 aluminium alloy", Science Direct, Vol.20(8), pp 1387-91.

[19] G.Athers: The welding of aluminium and its alloys, Woodhead Publishing Limited,(2002), ISBN 185573567 9, pp. 1-31, 150-154, $161-165$

[20] W.Yuan, R.S.Mishra, S.Webba, Y.L.Chen, B.Carison, D.R.Herling, G.J.Grant: Effect of tool design and process parameters on properties of Al alloy 6061 friction stir spot welds, journal of Materials Proessig Technoloy, Vol.211 (2011).pp.972-977

[21] Ugur Özdemir, Sami Sayer,Çınar Yeni, Bornova-Izmir, Effect of Pin Penetration Depth on the Mechanical Properties of Friction Stir Spot Welded Aluminum and Copper, Article in Materialprufung - April 2012 DOI: $10.3139 / 120.110322$

[22] Y.C.Chen, A.Gholinia, P.B.Prangnell:Interface structure and bonding in abrasion circle friction stir spot welding: A novel approach for rapid welding aluminium alloy to steel automotive sheet, Materials Chemistry and Physics 134 (2012), pp. 459-463

[23] Mukuna P. Mubiayi et al:Characterization of the intermetallic compounds in aluminium and copper friction stir spot welds, Materials Today: Proceedings 4 (2017) 533-540

[24] Shilling C, Santos JD (2002) Method and device for joining atleast two adjoining work pieces by friction welding: Patent Application No. US0179682 [P]. 2002-12-05

[25] X.W.Yang, T.Fu, W.Y.Li:Friction Stir spot welding:A review pm joint macro and microstructure, property and process modelling, advances in materials science and engineering, Vol.2014, Article ID 697170, (2014), pp.1-11

[26] Venukumar S, Yalagi S, Muthukumaran S (2013) Comparison of microstructure and mechanical properties of conventional and refilled friction stir spot welds in AA 6061-T6 using filler plate.Trans Nonferrous Metals Soc China 23:2833-2842

[27] Li YB, Wei ZY, Wang ZZ, Li YT (2013) Friction self-piercing riveting of aluminum alloy AA6061-T6 to magnesium alloy AZ31B. J Manuf Sci Eng 135:1-7. doi:10.1115/1.4025421

[28] Hu, Yuan, "Friction-stir riveting : mechanical testing of friction-stir riveting" (2015).Theses and Dissertations. 1864.

[29] Karthikeyan, L, Senthil Kumar, VS \& Padmanabhan, KA 2010a, 'On the role of process variables in the friction stir cast aluminum A319 alloy' Materials and Design, vol. 31, pp. 761-771.

[30] [30].Karthikeyan, L, Senthil Kumar, VS \& Padmanabhan, KA 2010b, 'Biaxial Stressing of Sheets of Friction Stir Processed Aluminum Alloy A319', Materials and Manufacturing Processes, vol. 25, pp.1297-1303

[31] Karthikeyan, L, Senthil Kumar, VS \& Padmanabhan, KA 2013, 'Investigations on superplastic forming of friction stir-processed AA6063-T6 aluminium alloy', Materials and Manufacturing processes, vol. 28, pp. 294-298.

[32] K.Prasad Rao, G.D.Janaki Ram, B.E.Stucker, Effect of FSP on corrosion resistance of Al-Cu alloy Gas tungsten arc welds, Materials and Design 31(2010) 1576-1580

[33] Puviyarasan, M \& Senthil Kumar, VS, Viswanathan, D, Padmanabhan, KA 2017, 'On Improving the Formability of AA6061/SiCp Composite Synthesized Using Friction Stir Processing', Materials Science \& Engineering Technology, WILEY-V C H VERLAG GMBH, Vol.48, Issue 10, pp. 998-1008.

[34] Douglas C. Hofmann, Kenneth S. Vecchio, Submerged friction stir processing (SFSP): An improved method for creating ultra-finegrained bulk materials. Material Science and Engineering A 402 (2005) 234-241.

[35] Douglas C.Hoffman, Kenneth S. Vecchio, Submerged Friction stir processing (SFSP): An improved method for creating ultra-finegrained bulk materials, Materials Science and Engineering A 402 (2005) 234-241.

[36] M.Puviyarasan, V.S.Senthil Kumar, Optimization of friction stir profess parameters in fabricating AA $6061 / \mathrm{SiCp}$ composites, Procedia Engineering, 2012

[37] Puviyarasan, M \& Senthil Kumar, VS 2012, 'Optimization of friction stir process parameters in fabricating AA6061/SiCp composites', Procedia Engineering, ELSEVIER Publications, no. 38, pp. 10941103.
[38] Puviyarasan, M \& Senthil Kumar, VS 2012, 'Microstructural evolution and mechanical behavior of AA6063/SiCp bulk composites fabricated using friction stir processing', Australian Journal of Mechanical Engineering(AJME), Institution of Engineers Australia, vol. 10, no. 2, pp. 111-118.

[39] Wang, W.; Shi, Q.; Liu, P.; Li, H.; Li, T. A novel way to produce bulk Sic reinforced aluminium metal matrix composites by friction stir processing. J. Mater. Process. Technol. 2009, 209, 2099-2103.

[40] S.Soleymani et al, Microstructurual and tribological properties of A15083 based surface hybrid composite produced by friction stir processing; wear 278-279(2012) 41-47

[41] B.Balamugundan, L.Karthikeyan, M.Puviyarasan, Feasibility of fabricating HDPE Nanocomposties using a specially designed friction stir process tooling system, Polymer(Korea), vol.42, No. 1, 2018

[42] Puviyarasan, M \& Senthil Kumar, VS 2015, 'An Experimental Investigation for Multi-Response Optimization of Friction Stir Process Parameters during Fabrication of AA6061/B4Cp Composites' Arabian Journal for Science and Engineering, Springer Publications, vol. 40, no. 6, pp. 1733-1741.

[43] Puviyarasan, M \& Senthil Kumar, VS 2014, 'Optimization of Friction Stir Process Parameters in Fabricating AA6061/B4Cp Composites', International Journal of Applied Engineering Research, vol. 9, no. 26, pp. 8989-8992

[44] Puviyarasan, M \& Senthil Kumar, VS 2016, 'Multi-Response Optimization of Friction Stir Process Parameters in Fabricating AA6061-SiCp Composites Using Desirability Function Analysis', Journal of the Balkan Tribological Association, Bulgaria. (Under Review)

[45] K.P. Rao, A. Sankar, H.K. Rafi, G.D.J. Ram, G.M. Reddy, Friction surfacing on nonferrous substrates: a feasibility study, International journal of advanced manufacturing technology (May 2012).

[46] A.A. van der Stelt et al. Cladding of Advanced Al Alloys Employing Friction Stir Welding, Key Engineering Materials, ISSN: 1662-9795, Vols. 554-557, pp 1014-1021

[47] Rodelas JM, Lippold JC, Rule JR, Livingston J (2011): Friction stir processing as a base metal preparation technique for modification of fusion weld microstructures. In: Mishra RS, Mahoney WW, Lienert TJ (Ed) Friction Stir Welding and Processing VI,Minerals, Metals \& Materials Society (TMS), pp. 21-36

[48] Pedro Vilaça, João Gandra and Catarina Vidal, Linear Friction Based Processing Technologies for Aluminum Alloys: Surfacing, Stir Welding and Stir Channeling, http://dx.doi.org/10.5772/52026

[49] Nagarajan Balasubramanian, Friction Stir Channeling: An Innovative Technique for Heat Exchanger Manufacturing, (2008). Doctoral Dissertation. 